
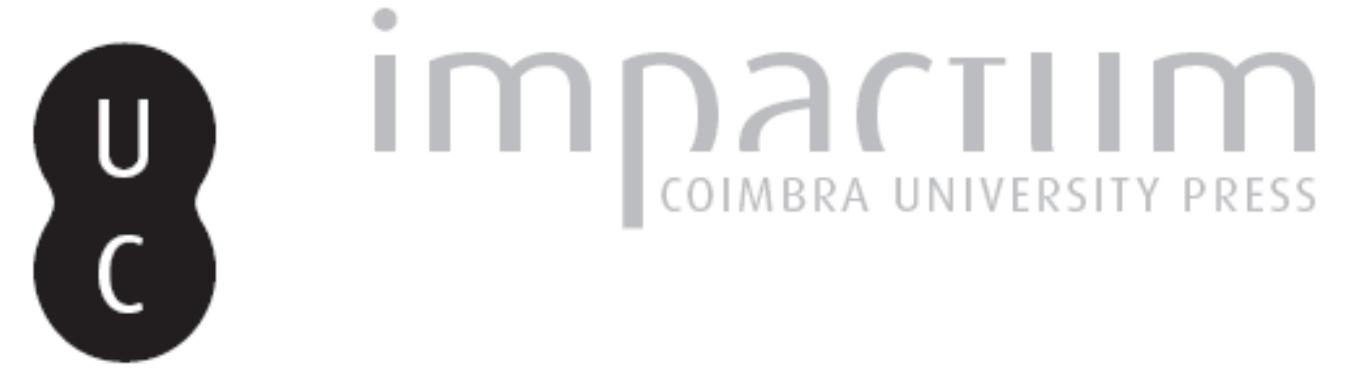

\title{
Aproximación al Vigo romano: (España)
}

Autor(es): Hidalgo Cuñarro, José Manuel

Publicado por: Imprensa da Universidade de Coimbra

URL persistente:

URl:http://hdl.handle.net/10316.2/45611

DOI:

DOI:https://dx.doi.org/10.14195/1647-8657_25_5

Accessed : $\quad$ 26-Apr-2023 01:28:00

A navegação consulta e descarregamento dos títulos inseridos nas Bibliotecas Digitais UC Digitalis, UC Pombalina e UC Impactum, pressupõem a aceitação plena e sem reservas dos Termos e Condições de Uso destas Bibliotecas Digitais, disponíveis em https://digitalis.uc.pt/pt-pt/termos.

Conforme exposto nos referidos Termos e Condições de Uso, o descarregamento de títulos de acesso restrito requer uma licença válida de autorização devendo o utilizador aceder ao(s) documento(s) a partir de um endereço de IP da instituição detentora da supramencionada licença.

Ao utilizador é apenas permitido o descarregamento para uso pessoal, pelo que o emprego do(s) título(s) descarregado(s) para outro fim, designadamente comercial, carece de autorização do respetivo autor ou editor da obra.

Na medida em que todas as obras da UC Digitalis se encontram protegidas pelo Código do Direito de Autor e Direitos Conexos e demais legislação aplicável, toda a cópia, parcial ou total, deste documento, nos casos em que é legalmente admitida, deverá conter ou fazer-se acompanhar por este aviso.

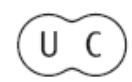


FACULDADE DE LETRAS

INSTITUTO DE ARQUEOLOGIA

CONIMBRIGA

$V O L U M E X X V$

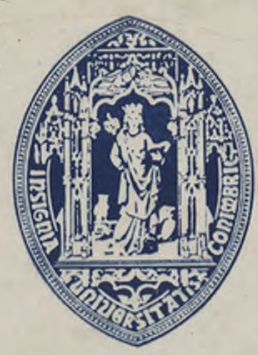

UNIVERSIDADE DE COIMBRA

1986 
JOSÉ MANUEL HIDALGO CÜNARRO

Departamento de Prehistoria y Arqueologia del Museu Municipal «Quiñones de Leon», de Vigo

\section{APROXIMACIÓN AL VIGO ROMANO (ESPAÑA)}

«Conimbriga», XXV, (1986), p. 75-87

Resumen: En este pequeño artículo se estudian y sintetizan las evidencias más claras que poseemos de la ciudad de Vigo (España), en época romana.

Así se analizarán sus tipos de poblamiento (villas, castros, edificaciones diversas, ...) y sus enterramientos (necrópolis) localizados hasta la actualidad.

Se resalta el papel importante que poseyó el comercio atlántico romano con este enclave, que nos viene dado sobretudo por los restos arqueológicos submarinos encontrados en las costas viguesas.

Podemos señalar que llama la atención el temprano contacto que posee esta área goegráfica con el mundo romano (Itália, Sur de Francia y diferentes puntos de la península Ibérica), asi como el fuerte grado de romanización que se producirá en la zona, tras la conquista romana del Noroeste Peninsular.

Résumé : L'auteur fait le point des données dont on dispose sur l'occupation romaine de Vigo et présente un inventaire des vestiges d'habitats et nécropoles dans la région, qui a été profondément romanisée.

Les vestiges archéologiques trouvés en mer aux environs de Lugo témoignent l'importance du commerce atlantique dans la côte galicienne. Le commerce s'est dévellopé avec l'Italie, le sud de la France el plusieurs régions de la Péninsule Ibérique dès l'occupation romaine du nord-ouest à l'époque d'Auguste. 
(Página deixada propositadamente em branco) 


\section{APROXIMACION AL VIGO ROMANO (ESPAÑA)}

Numerosos hallazgos arqueológicos localizados dentro del término municipal vigués, ponen en evidencia la extraordinaria importancia que tuvo Vigo en época romana.

En este breve estudio, analizaremos de forma resumida dos aspectos muy concretos: los tipos de poblamiento o habitat existente en Vigo en época romana y sus características principales (las villas, los castros romanizados, edificaciones sin concretar su función, asi como los restos arqueológicos submarinos que nos hablan del intenso tráfico comercial que mantenía dicha población con el resto de la península ibérica y otros puntos geográficos fuera de ella); y las necrópolis o enterramientos romanos que hasta la actualidad se han podido documentar en nuestra zona y que jalonan de forma bien visible el litoral vigués.

\section{Las villas romanas}

Se han localizado, hasta el momento, dos villas marítimas de época romana en Vigo. Se trata de la situada en el lugar de «Toralia» y la que se ubica en Sobreira.

La villa romana de Toralia se emplaza en Cánido, enfrente a la isla que lleva dicho nombre, al final de la playa del Bao, hacia el Sur. En la actualidad está ocupada por la finca denominada «Mirambell».

Hoy día se pueden ver en un espacio rectángular de unos 16 metros de largo por 13 de ancho, diversos compartimentos o estancias en su interior, pertenecientes a la mencionada villa.

Conimbriga, 25 (1986), 75-87 
Fruto de antiguas excavaciones se localizaron diversos objetos que fechan la misma hacia el siglo $\mathrm{m}$ al iv después de Jesucristo. De todo este material arqueológico podemos destacar: un capitel de granito de orden corintio; cerámida pintada con temas animalísticos y geométricos; «terra sigillata» hispánica; un pico de hierro; cerámica común de mesa y cocina (jarra, cuenco con visera, copa...); «pondus»; vidrio; etc. (Hidalgo Cuñarro y Costas Goberna, 1982, pp. 351 y ss.).

Interesante es la colección de monedas romanas que ha dado esta villa. Se trata de tres antonianos, cuarenta y seis medianos bronces que corresponden a los siguientes emperadores: Galieno (253-268); Claudio II (268-270); Magnencio (306-312); Constantino I (307-337); Constantino II (317-337); Constancio II (337-361); y Constante I (333-350).

El marco cronológico nos vendría dado por el antoniano de Galieno (253-268) a los tres medianos bronces de Constancio II (337-361) (Juega Puig, 1982, pp. 367 y ss.).

En la parroquia de Oia, en un espolón que se adentra hacia el mar, en la denominada playa de «Sobreira», se documenta la otra villa romana viguesa, pero por haberse realizado hace tiempo obras en dicha zona, puede decirse que en la actualidad se encuentra casi totalmente destruido dicho yacimiento arqueológico. En él se pudieron ver diversos muros construidos con sillares muy bien trabajados, así como en alguna zona, contemplar pavimentos de «opus signinum». En cuanto a objetos arqueológicos encontrados en esta villa, tenemos varios fragmentos de cerámica pintada y «terra sigillata» hispánica; ladrillos y «tegulae»; cerámica común de cocina; ánforas... que fechan este yacimiento hacia los siglos $\mathrm{m}$ y iv después de Jesucristo (Hidalgo Cuñarro, 1984, pp. 83 e ss.).

\section{Los castros romanizados}

Podemos apuntar que la totalidad de los castros catalogados hasta la actualidad en el «Val do Fragoso», poseen evidencias claras de haber sufrido (en mayor o en menor medida) el proceso de romanización, a juzgar por los restos arqueológicos (estructuras, ánforas, «tegulae» e imbrices», cerámica común romana...) locali- 
zados en dichos emplazamientos (Hidalgo Cuñarro y Costas

Goberna, 1983, pp. 160 y ss.).

De los 24 castros documentados dentro del término municipal vigués, sin lugar a dudas, es el conocido Castro de Vigo (situado en pleno centro de la ciudad) el que más detalles nos ofrece de dicho período, gracias a las excavaciones arqueológicas sistemáticas que se están llevando a cabo en el mismo.

La romanización del Castro de Vigo nos viene definida, por un lado, por las nuevas estructuras que se construyen en ese momento, asi como por cambios «urbanísticos» en diferentes zonas de habitat. Por otro lado, tenemos una gran cantidad de objetos importados que reflejan claramente el intenso comercio romano y el alto nivel económico de vida que poseían determinados sectores de habitantes del mencionado poblamiento. A continuación y de forma resumida pasaremos revista a los materiales arqueológicos que nos hablan de dicho aspecto y que fueron localizados en las últimas campañas arqueológicas realizadas (Hidalgo Cuñarro, 1981, 1983 y 1985).

Se localizaron varios fragmentos de cerámica campaniense de los tipos B y C y que son fechables desde la mitad del siglo $\mathrm{n}$ hasta mediados del siglo $\mathrm{i}$ antes de Jesucristo. En su tipología, estas vasijas imitan formas metálicas en su mayoría y proceden de Etruria (Lamboglia, 1952; Morel, 1981 y Sanmarti-Grego, 1978).

Datables desde el 50/40 antes de Jesucristo al 30/40 después de Jesucristo, tenemos diversos fragmentos y una marca de alfarero en «terra sigillata» itálica. También poseemos diferentes fragmentos lisos y decorados, así como una marca de alfarero, en «terra sigillata» sudgálica, datable desde el 20/40 al 150 después de Jesucristo (Beltran Lloris, 1978, pp. 74 y 77).

De cerámica marmorata se encontraron diversas formas, que corresponden a pequeños cuencos y copas. Como se recordará, este tipo cerámico está producido por el taller gálico de La Graufesenque y su cronología se sitúa entre Claudio-Vespasiano. Es muy escasa en el Noroeste peninsular, pero abundante en el litoral del Mediterráneo (Balil, 1982, pp. 179-180). Muy abundante fueron las formas lisas $\mathrm{y}$ decoradas de «terra sigillata» hispánica encontradas. Se pudieron documentar cuatro marcas de alfarero, que las relaciona con diferentes talleres de la - península ibérica. Esta 
producción cerámica posee un amplio marco cronológico que va del siglo i a iv después de Jesucristo (Mezquiriz de Catalan, 1961; y Mayet, 1984).

Tenemos también fragmentos lisos y decorados de «terra sigillata» clara $\mathrm{D}$, fechable del iv al $\mathrm{v}$ después de Jesucristo $\mathrm{y}$ muy poco frecuente en yacimientos gallegos (Caamaño Gesto, 1983, p. 243).

Se encontraron asimismo varios fragmentos de lucernas de volutas de época Julio-Claudia (Fernandez y Manera, 1980) y diversos vasitos y cubiletes de cerámica de paredes finas, presentando los primeros de ellos decoración a la barbotina de buena calidad. Este tipo de cerámica podemos datarlo desde los ultimos años del siglo ii antes de Jesucristo al i después de Jesucristo, siendo muy abundantes en época de Octavio Augusto (Mayet, 1975).

Fueron muy numerosos los fragmentos recogidos pertenecientes a cerámica común romana. De cerámica de cocina podemos señalar platos de borde engrosado y bífido, así como fuentes de barniz rojo-pompeyano. De cerámica de mesa, vasos, jarras y tacitas. Todo ello fechable entre los tres primeros siglos de nuestra era (Vegas, 1973, pp. 11 y ss.; y Tuffreau-Libre, 1980). De ánforas, podemos distinguir republicanas (Dressel 1) del siglo II al $\mathrm{i}$ antes de Jesucristo, e imperiales (sobre todo la familia Dressel 7/11) de los siglos $\mathrm{i}$ al $\mathrm{m}$ después de Jesucristo. Se pudieron documentar dos marcas de alfarero (Beltran Lloris, 1970).

En cuanto a monedas romanas tenemos: un quinario $y$ un as de Octavio Augusto (27 antes de Jesucristo al 14 después de Jesucristo); un denario de Vitelio (69 después de Jesucristo); un as de Trajano (98 al 117 después de Jesucristo); un as de Octavio Augusto con la «caetra» en el reverso (27 al 23 antes de Jesucristo); un sextercio y un as de Adriano (117-138 después de Jesucristo); y un sextercio de Agrippa (39 al 27 antes de Jesucristo) (Beltran Martinez, 1976, pp. 95 y ss.; Harold Mattingly, 1965, pp. 372 y ss.; Beltran Martinez, 1950, pp. 224 y ss.; Caamaño Gesto, 1979, pp. 67-76; Lafuente, 1877; Zander, 1959; Sear, 1981, etc.).

Poseemos también un pequeño entalle de cara plana y forma oval, en el que podemos ver representada una cuadriga y un auriga, pudiéndose datar esta excepcional pieza hacia mediados del siglo i después de Jesucristo. Hemos de recordar aquí otra impor- 
tante muestra de glíptica romana vinculada a la ría de Vigo. Nos referimos al anillo de oro encontrado en la isla Norte de las Cíes que tiene un entalle con un jabalí y una interesante inscripción, datándose esta joya hacia el siglo $\mathrm{n}$ después de Jesucristo (Casal Garcia, 1980, pp. 103 y 104).

Por último tenemos fichas de juego de pasta vitrea, cuentas de collar o pulsera de diferentes tonalidades, frecuentes en castros muy romanizados y de cronología amplia (Martinez Tamuxe, 1983, pp. 103 y 138) y varios fragmentos de vidrio de cuencos de costillas, objetos muy frecuentes en el siglo i después de Jesucristo (Vigil Pascual, 1969, pp. 103 y ss.).

Por todo lo expuesto podemos ter como el Castro de Vigo va a sufrir una profunda romanización y ésta va a ser temprana y a la vez fuerte y continua. El siglo de mayor esplendor para este poblamiento (teniendo en cuenta los materiales arqueológicos recogidos) será todo el siglo i después de Jesucristo e inicios del siglo siguiente.

\section{Edificaciones romanas sin concretar su función}

En este apartado analizamos una serie de puntos en los que se han localizado diversas estructuras y/o piezas arqueológicas datables en época romana, pero que por lo parcial de los hallazgos no podemos concretar con certeza la función que podían tener las mencionadas construcciones y/o lo que nos revelan los objetos romanos encontrados de forma aislada $\mathrm{y} \sin$ apenas contexto arqueológico. Nos evidencian, eso sí, lugares de habitat romano que podían ser de diversa índole y desempeñar distinta función, en relación al poblamiento de la zona en dicho período histórico.

Asi tenemos que según referencias antiguas, en la playa del Arenal, se descubrieron restos arqueológicos romanos de diversas construcciones asi como monedas y tégulas.

En el arenal de Coía y cercanías, también se localizaron restos de edificaciones antiguas, monedas y tejas romanas, según viejas fuentes bibliográficas. Más recientemente, detrás del edificio de la casa Mar, se encontró una gran base romana que actualmente se exhibe en el Museo Municipal «Quiñones de León» de Vigo, y a 
su lado se recogieron numerosos fragmentos de tégulas y cerámica galaico-romana. Procedentes del lugar de «A Oliveira» en Teis, poseemos varias columnas toscamente labradas, una basa de reducidas dimensiones y una pila exagonal con agujero en el centro. Además se recogieron tres ladrillos con posibles representaciones zodiacales. Todo ello se encuentra en el Museo Municipal vigués.

Para finalizar este apartado podemos señalar que: en la Florida se encontraron diversas tégulas; en la calle Alfolíes de Bouzas, ánforas romanas; cerca de la estación de FF. CC. varias ánforas; en diferentes puntos del centro de la ciudad, molinos circulares de mano y pequeños morteros de granito; etc. (Rodrigues Seoane y Diaz Alvarez, 1973, pp. 60 y ss.; Filgueira Valverde y Garcia Alen, 1956; y Alvarez Blazquez, Costas Goberna e Hidalgo Cuñarro, 1980, pp. 41 y ss.).

Hallazgos submarinos de época romana

El litoral vigués es rico en hallazgos arqueológicos submarinos de esta época. Se tratan, en su gran mayoría, de ánforas romanas que poseen una cronología que va desde el cambio de era hasta el siglo iv después de Jesucristo. Evidencian un intenso tráfico comercial del poblamiento que analizamos anteriormente con otras áreas. Podemos mencionar el hallazgo de restos anfóricos en la dársena 1 y 2 del muelle vigués; en las cercanías de la isla de Toralia; en la dársena de Bouzas; y por último en el denominado Cabo do mar, en donde existe la posibilidad de que se localice un pecio, por la gran cantidad de ánforas recuperadas y que en la actualidad se custodian en el Museo municipal de Vigo (Diaz Alvarez, 1981, pp. 37 y ss.; y 1984, pp. 29 y ss.; Hidalgo Cuñarro y Sotelo Solana, 1985, pp. 127e ss.; y Gonzalez Fernandez, 1983, pp 73-98).

Las necropolis romanas

En diversos lugares del término municipal vigués se localizaron restos de enterramientos que nos documentan en cierta medida algunas de las necrópolis romanas existentes en nuestra zona de estudio. Al lado de noticias confusas de hallazgos de este 
tipo tenemos otras que nos indican con certeza el emplazmiento de varias de ellas.

En Alcabre, en la finca conocida como «Fundíales» se localizó una lápida funeraria dedicada a los dioses Manes y que actualmente se guarda en el Museo de Pontevedra (Rodríguez Lage, 1974, p. 39).

Luego tenemos dos referencias bastante confusas y parciales. Una nos indica que en la antigua Plaza de las Gallinas, en la esquina entre las calles de la Gamboa y Carral, se encontró un «doble sepulcro» construido a base de ladrillos, en cuyo interior había restos humanos. La otra señala que en el lugar de «San Gregorio» entre Bouzas y Vigo, se localizaron «urnas de ladrillos».

Con certeza sabemos que existía una necrópolis romana entre la zona de Picacho y la antigua playa de San Francisco. En esta zona se pusieron al descubierto tres sepulturas formadas por tégulas, una de las cuales estaba completa y presentaba el típico «tejadillo a dos vertientes».

De mayor importancia sería la necrópolis de la isla de Toralia. Sabemos que estaba situada hacia la zona media de dicha isla y la formaban diferentes sepulturas de forma trapezoidal, construidas a base de lajas de granito y pizarra, en sus paredes, fondo y cubierta. En ellas aparecieron numerosos esqueletos y abundante ajuar funerário. De este material arqueológico, destaca el estilo de bronce encontrado en una sepultura y que tipológicamente nos viene dado por un instrumento metálico alargado que posee en su terminación una parte afilada en la punta (a manera de punzón) y por el lado opuesto se puede observar un pequeño rebaje (en forma de espátula). Presenta decoración incisa muy simple, pesa 43 gramos y mide $184 \mathrm{~mm}$ de largo (Hidalgo Cuñarro, 1983a, pp. 37 y ss.). Por su paralelismo con otras necrópolis romanas de Galicia, podemos datarla hacia los siglos iv-v después de Jesucristo (Carro Otero, 1972, pp. 124-129).

Finalmente tenemos que en la calle Pontevedra, cerca de la antigua playa del Arenal, se encontraron un total de 29 estelas (entre enteras y fragmentadas) y un ara. Este extraordinario conjunto se custodia en el Museo Municipal de Vigo.

Estas lápidas funerarias romanas nos informan de diversos aspectos interesantes para el conocimiento del Vigo romano. 
Aparte de los datos que ofrecen para el estudio particular del arte provincia! romano en nuestra área geográfica, atendiendo a los motivos que se pueden observar en las mencionadas estelas, también gracias a sus inscripciones, nos documentan, entre otras cosas, acerca de los índices de mortalidad en dicha época o de la emigración de personas de la Meseta castellana hacia el Vigo romano. Esta valiosa colección epigráfica ha merecido numerosos estudios por parte de diferentes autores (Alvarez Blazquez, 1953, pp. 462-475; Alvarez Blazquez y Bouza Brey, 1961, pp. 6 y ss.; Julia, 1971; Garcia Merino, 1973, pp. 9-28; y Acuña Castroviejo, 1979, pp. 39-53).

\section{Conclusiones previas}

En esta pequeña aproximación al Vigo romano, en primer lugar, llama la atención el temprano contacto que posee esta área geográfica del Noroeste peninsular con el mundo romano, así como el rápido y fuerte grado de romanización que se produce después de la conquista de Galicia por las legiones de Roma.

A manera de conclusiones previas, podemos apuntar lo siguiente:

Algunos castros vigueses continúan habitados hasta el siglo $\mathrm{m}$ después de Jesucristo (como el Castro de Vigo), pero otros ya son abandonados hacia finales del siglo i después de Jesucristo (como el castro de la isla de Toralia). En los primeros, tenemos sin embargo que el habitat se desplaza hacia las laderas del enclave castreño, posiblemente ya fuera de su recinto amurallado, ya que dichas defensas no poseen en esta época justificación alguna.

Aparece un tipo nuevo de habitat: la villa romana. Las dos que tenemos son de época tardía, ya de los siglos m-iv después de Jesucristo. Otro tipo de habitat nos viene dado por esas construcciones de las que no podemos concretar su función, pero que, como característica general, se encuentran en zonas llanas, cercanas al litoral.

Los restos arqueológicos submarinos nos reafirman la importancia del Vigo de los primeros siglos de nuestra era. 
Por último, las diversas necrópolis descubiertas hasta la actualidad evidencian claramente una activa y numerosa población en esas fechas.

Hemos de esperar nuevos datos para acercarnos con más detalle a la etapa romana de Vigo que, sin duda, ya a juzgar por lo aquí expuesto, fue extraordinariamente fecunda e importante.

Los dibujos del presente articulo los realizó José Manuel Rodriguez Sobral. Para él, mi sincero agradecimiento.

\section{REFERÊNCIAS BIBLIOGRÁFICAS}

Acuña Castroviejo, Fernando, 1979, Vigo en la A?itigüedad, en la obra «Vigo en su Historia», Vigo.

Alvarez Blazquez, José María, 1953, Hallazgos de estelas funerarias romanas en Vigo (Pontevedra), III Congresso Nacional de Arqueología.

Alvarez Blazquez, José María y Bouza Brey, Fermín, 1961, Inscripciones romanas de Vigo, «Cuadernos de Estudios Gallegos», tomo XVI, fascículo 48 .

Alvarez Blazquez, José María, Costas goberna, Fernando Javier e Hidalgo Cuñarro, José Manuel, 1980, Vigo arqueológico, «Revista del Museo Municipal ‘Quiñones de Léon’ de Vigo» n. ${ }^{\circ} 2$.

Balil, A., 1982, Notas de cerámica romana (III), «Boletín del Seminario de Arte y Arqueología de la Universidad de Valladolid», tomo XLVIII.

Beltran Lloris, M., 1970, Las ánforas romanas en España, Zaragoza.

-----, Cerámica romana: tipología y clasificación, Zaragoza.

Beltran Martinez, A., 1950, Curso de Numismática, Zaragoza.

----, , 1976, Las monedas romanas de Mérida: su interpretación histórica, Augusta Emerita, Actas del Bimilenario de Mérida, Madrid.

Canmaño Gesto, J. M., 1979, Aportaciones al estudio de las monedas de la «caetra»: Las monedas de la colección Blanco Cicerón (La Coruña), «Boletín auriense», tomo IX.

----- , 1983, Cerámicas finas de importación en la época romana en Galicia,

En la obra «Estudos de cultura castrexa e de historia antigua de Galicia», Santiago de Compostela.

Car ro Otero, José, 1972, Antropología, Gran Enciclopedia Gallega, Tomo II.

Casal García, Raquel, 1980, Pedras de anelo do Noroeste Peninsular, Revista «Gallaecia», 6.

Diaz Alvarez, Pedro, 1981, Anforas romanas en los caminos del mar, Vigo.

----, 1984, Anforas romanas en el eje atlántico galaico-lusitano, Vigo. 
Fernandez, Jorge y Manera, Esperanza, 1980, Lucernas romanas del Museo Arqueológico de /biza, Trabajos del Museo Arqueológico de Ibiza, tomo I.

Filgueira Valverde, José y García Alen, A., 1956, Materiales para la carta: arqueológica de la provincia de Pontevedra, «El Museo de Pontevedra», tomo VIII.

García Merino, C., 1973, Las tierras del NO. foco de atracción para los emigrantes de la meseta en época romana, «Hispania Antiqua», III.

Gonzalez Fernandez, X. M., 1983, O comercio romano na ría de Vigo, Revista «Brigántium», vol. 4.

Harold Mattingly, M. A., 1965, Coins of the Roman Empire in Rritish Museum, London.

Hidalgo Cuñarro, José Manuel, 1981, El Castro de Vigo. Noticia preliminar de las excavaciones arqueológicas de 1981, «Revista del Museo Municipal 'Quiñones de León' de Vigo», n. ${ }^{\circ} 5$.

----, 1983, Excavaciones arqueológicas en el Castro de Vigo, «Revista del Museo Municipal 'Quiñones de León' de Vigo», n. ${ }^{\circ} 6$.

----- , 1983a, Estudio de los materiales arqueológicos de la isla de 1 oralla (Vigo, Pontevedra), Tesis de licenciatura leida en la Facultad de Geografía e Historia de la Universidad de Santiago de Compostela (mecanografiada).

-----, 1984, La Prehistoria y la Arqueología de la actualidad, «Revista del Museo Municipal 'Quiñones de León’ de Vigo», n. ${ }^{\circ} 7$.

-----, 1985, Memoria de las excavaciones arqueológicas realizadas en el Castro de Vigo (Pontevedra) durante 1983, Serie de publicaciones de la Dirección Xeral do Patrimonio Artístico e Monumental da Xunta de Galicia, «Arqueología/Memorias», n. ${ }^{\circ} 1$.

hidalgo Cuñarro, José Manuel y Costas Goberna, Fernando Javier, 1982, La villa romana de Torralla, «El Museo de Pontevedra», tomo XXXVI.

----, 1983, Asentamientos cástrenos en los valles Fragoso y Minor (Pontevedra), Actas del II Seminario de Arqueología del Noroeste Peninsular, Santiago de Compostela.

Hidalgo Cuñarro, José Manuel y Sotelo Solana, J. C., 1985, Apuntes para la carta arqueológica de la Ría de Vigo, Actas del VI Congreso Internacional de Arqueología submarina, Cartagena.

Juega Puig, Juan, 1982, Las monedas romanas de la villa, romana de Toralia, «El Museo de Pontevedra», tomo XXXVI.

Julia, D., 1971, Etude epigráphique et iconographique des steles funeraires de Vigo, Heidelberg.

LAF U e N TE, M., 1877. Historia general de España, Barcelona.

Lambоglia, Niño, 1952, Per una clasificazione preliminary della cerámica campana, Bordighera.

Martinez Tamuxe, X., 1983, Citania y Museo Arqueológico de Santa Tecla, A Guardia. 
MaYet, F., 1975, Les céramiques à parois fines dans la Péninsule Ibérique, Par s.

---- , 1984 Les céramiques sigillêes hispaniques. Contribution à Vhistoire économique de la Peninsule Ibérique sous VEmpire Romain, Paris.

Mezquiriz de Catalan, M. ${ }^{a}$ xVngeles, 1961, Terra sigillata hispánica, Tomo I y II, Valencia.

Morel, Jean Paul, 1981, Céramique campanienne. Les formes, texto y láminas, Roma.

Rodriguez Page, Sara, 1974, Las estelas funerarias de Galicia en la época romana, Orense.

Rodríguez Secane, M. ${ }^{\text {a }}$ del Carmen y diaz Alyarez, Pedro, 1973, Noticias de Prehistoria en torno a Vigo y su ría, Vigo.

SANMARTI-GRego, 1978, La cerámica campaniense de Emporion y Rhode, Tomo I y II, Barcelona.

SEAR, David, 1981, Roman Coins, London.

TUFFREAU-LiBRE, 1980, La céramique commune gallo-romaine dans le nord de la France (Nord, Pas-de-Calais), Dille.

Vegas, Mercedes, 1973, Cerámica común romana del Mediterráneo Occidental, Barcelona.

Vigil Pascual, M., 1969, El vidrio en el Mundo Antiguo, Madrid.

ZANDE R, 1959, Roman Imperial Coins, Winsconsin. 
(Página deixada propositadamente em branco) 

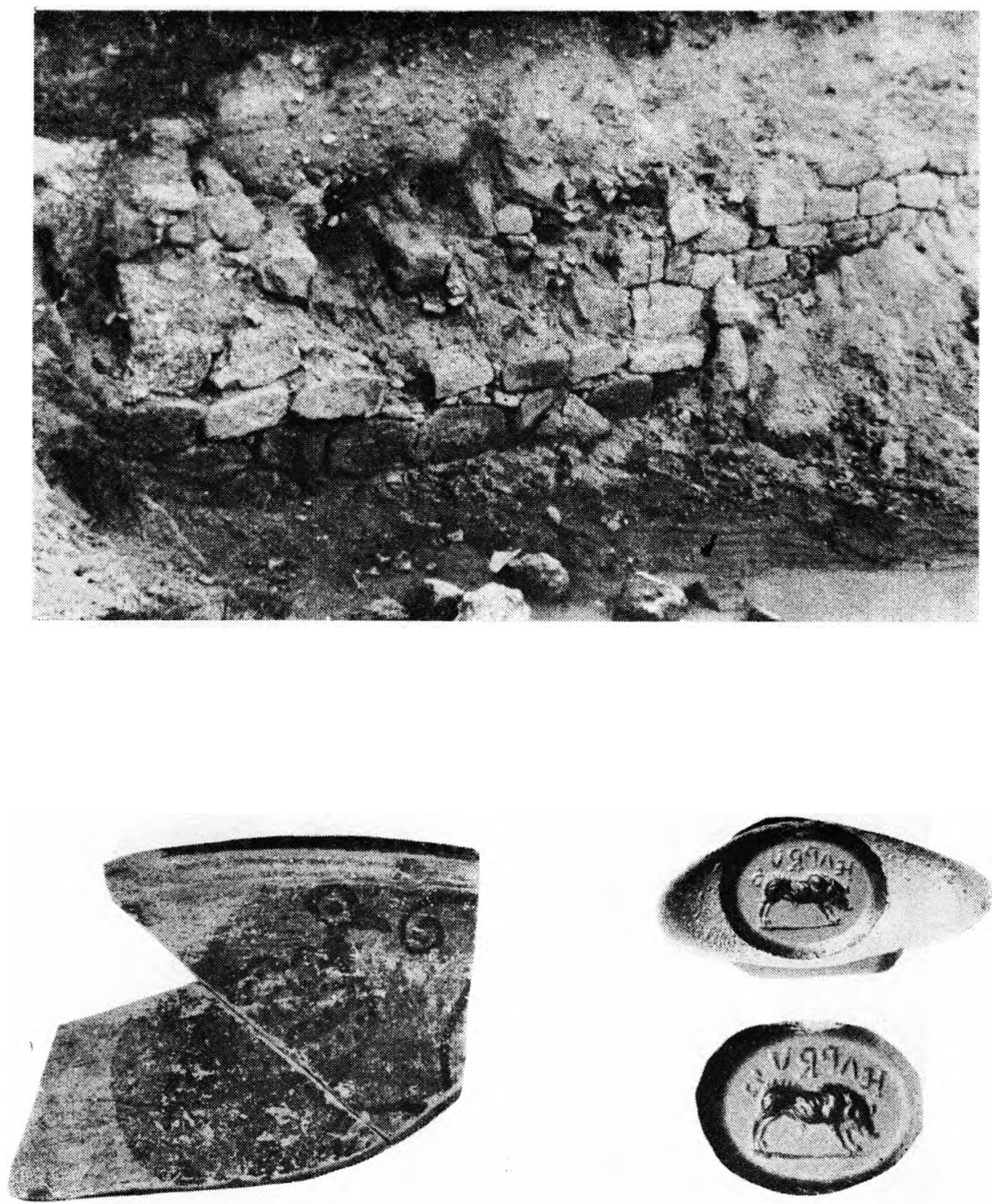

I - Restos de la villa romana de Sobreira. Cerámica pintada de la villa romana de Toralia. Anillo romano de las islas Cíes. Detalle del jabalí y la leyenda que se puede observar en el entalle del mismo. 


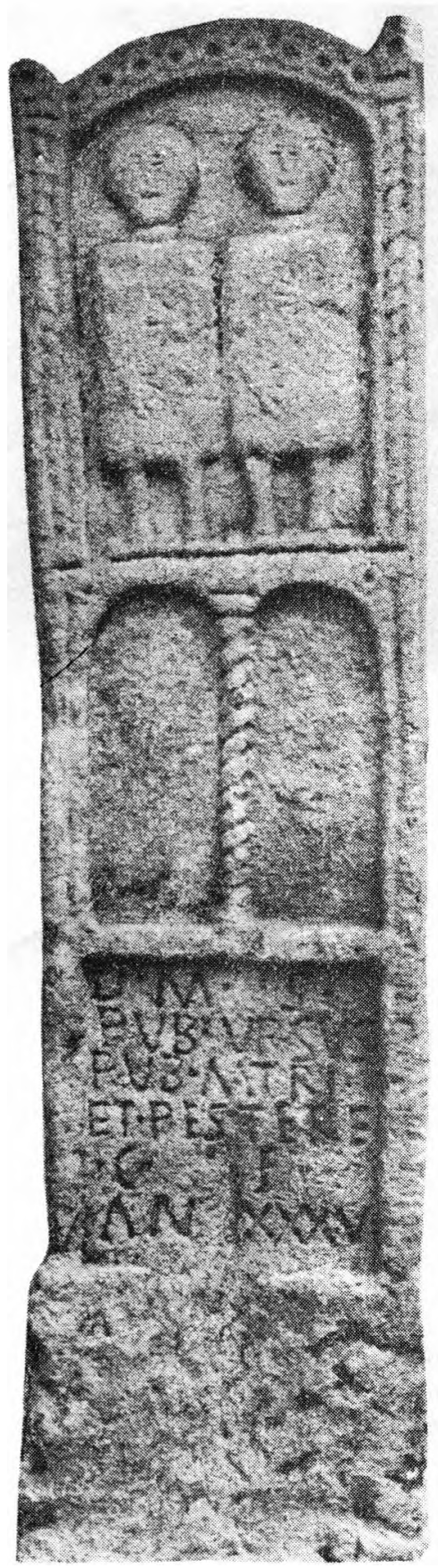

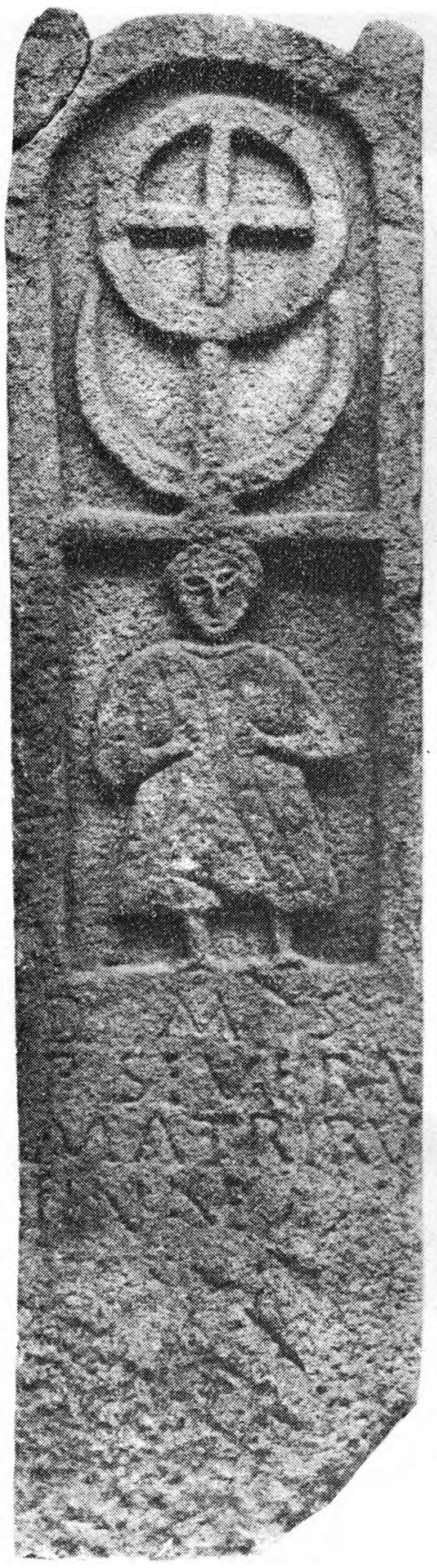

II — Estelas romanas de Vigo (Foto: R. Friedrich) 
LAMINA III

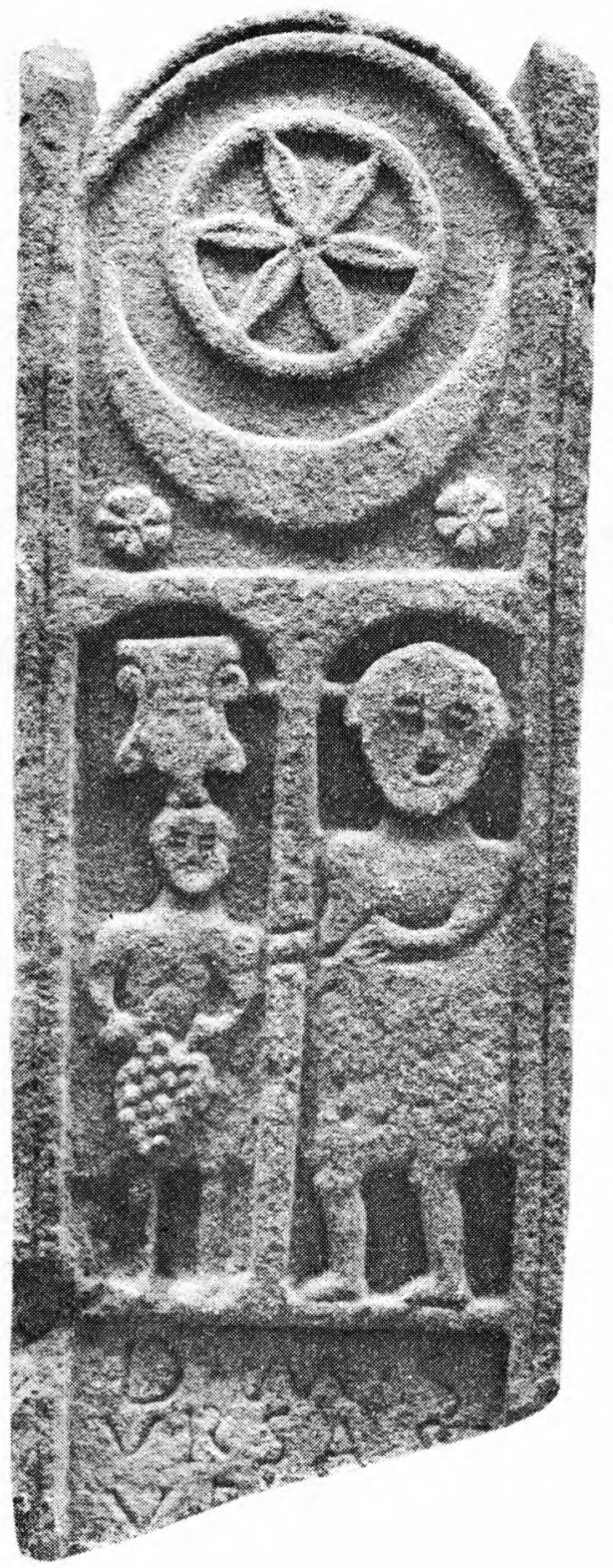

III — Estela romana de Vigo (Foto: R. Friedrich) 


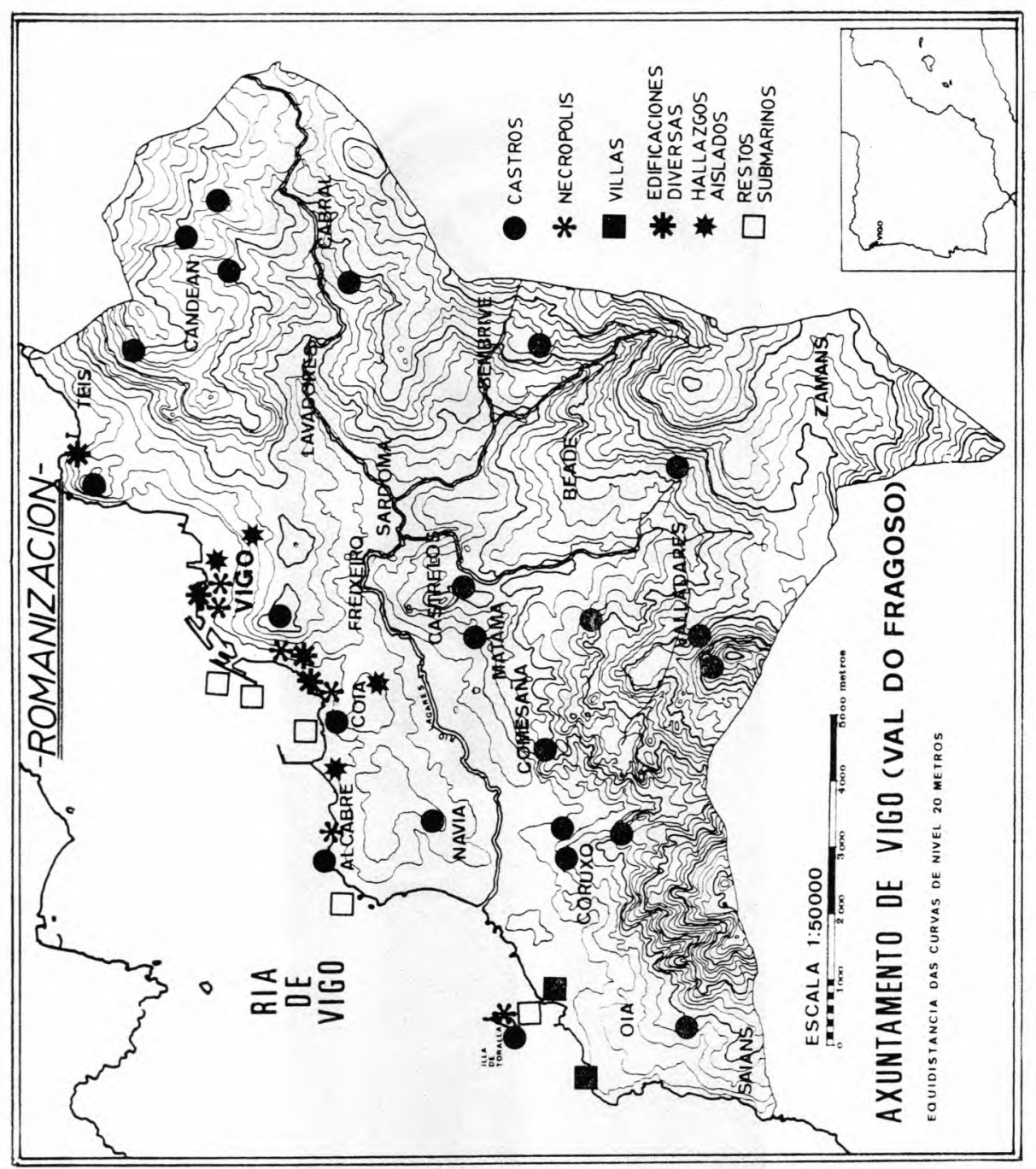

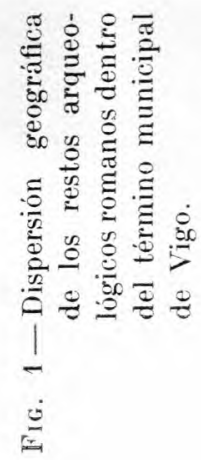



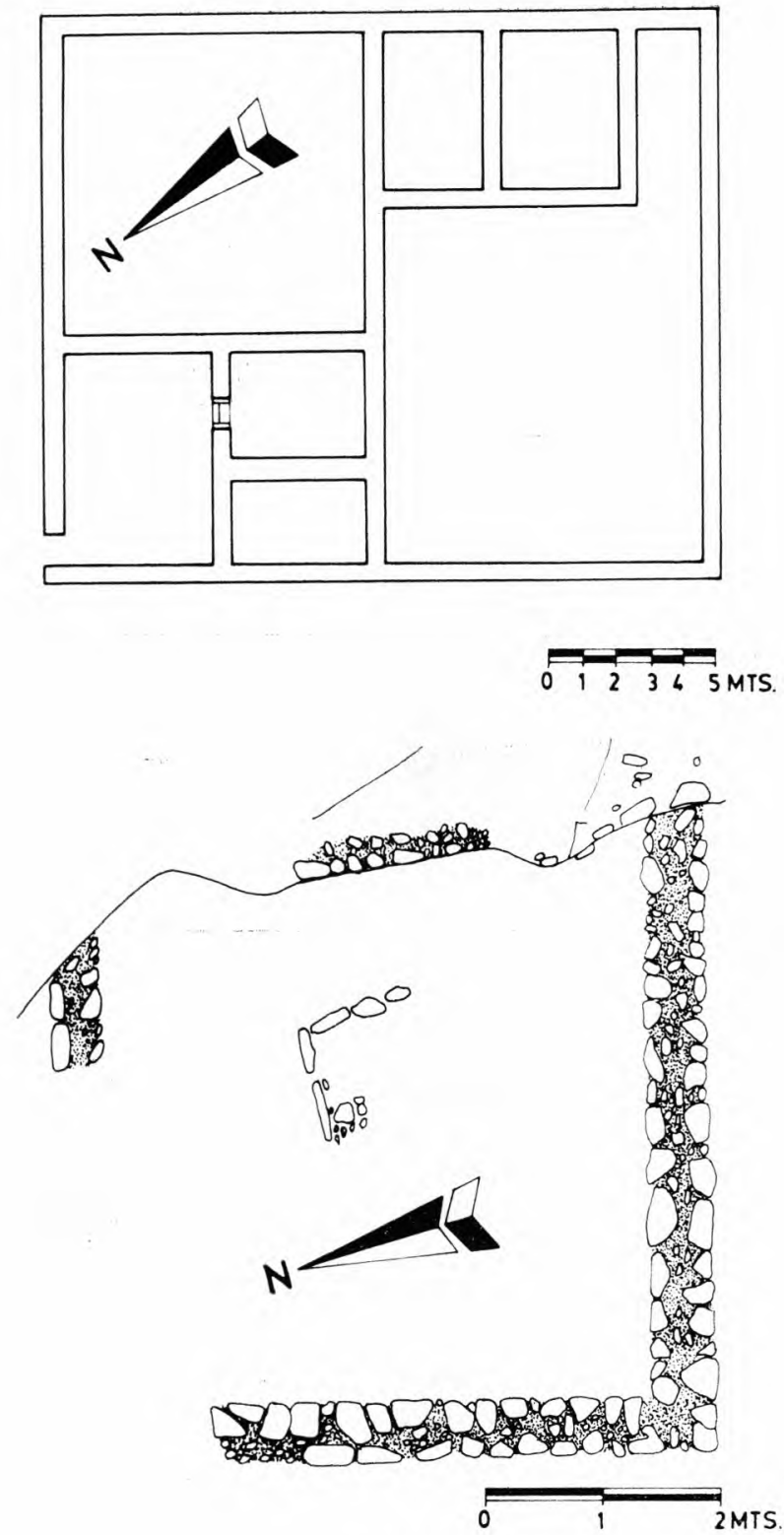

FIG. 2

Arriba, estancias de la villa de Toralia (siglos III-IV después de Jesucristo. Abajo, vivienda del Castro de Yigo (siglos I-II después de Jesucristo). 

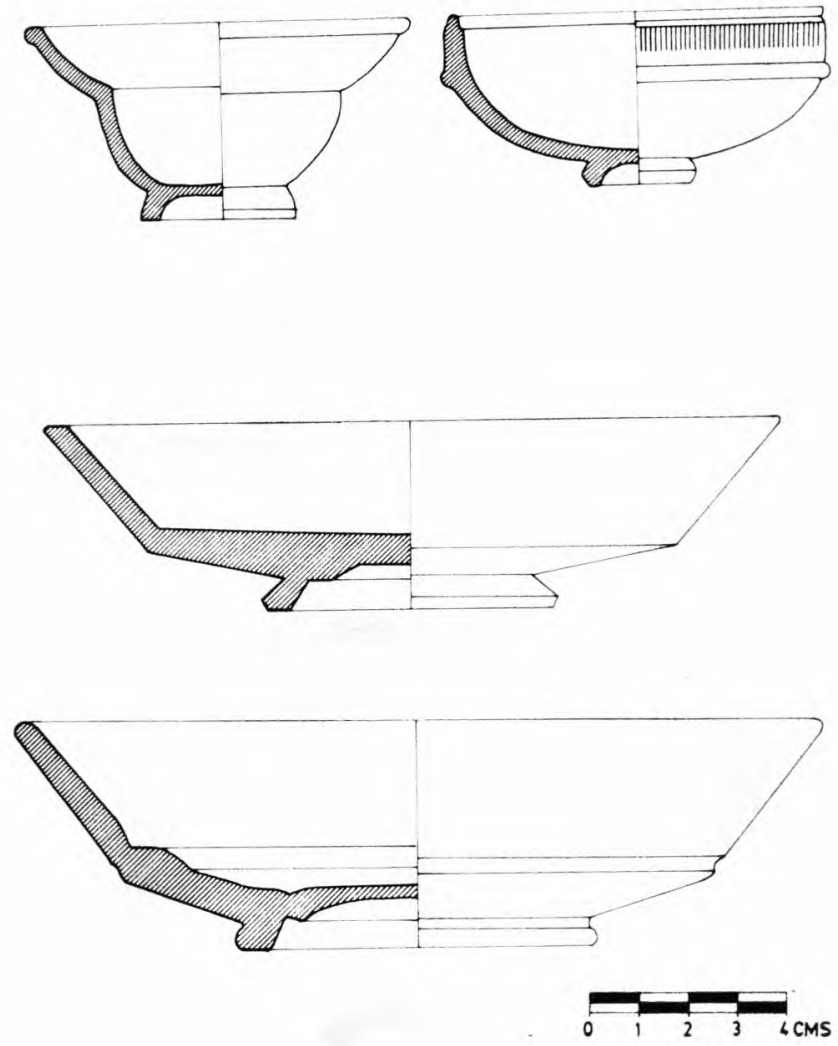

FIG. 3

«Terra sigillata» hispánica del Castro de Vigo. 

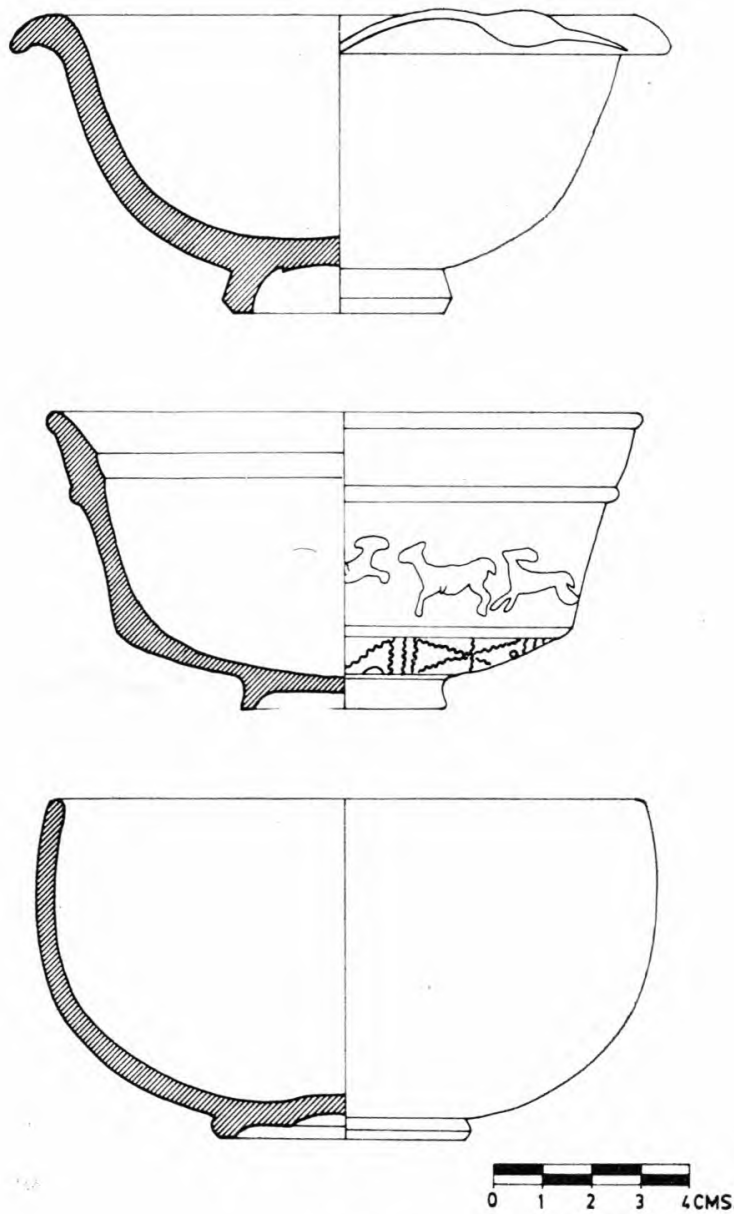

FIG. 4

«Terra sigillata» hispánica del Gastro de Vigo. 

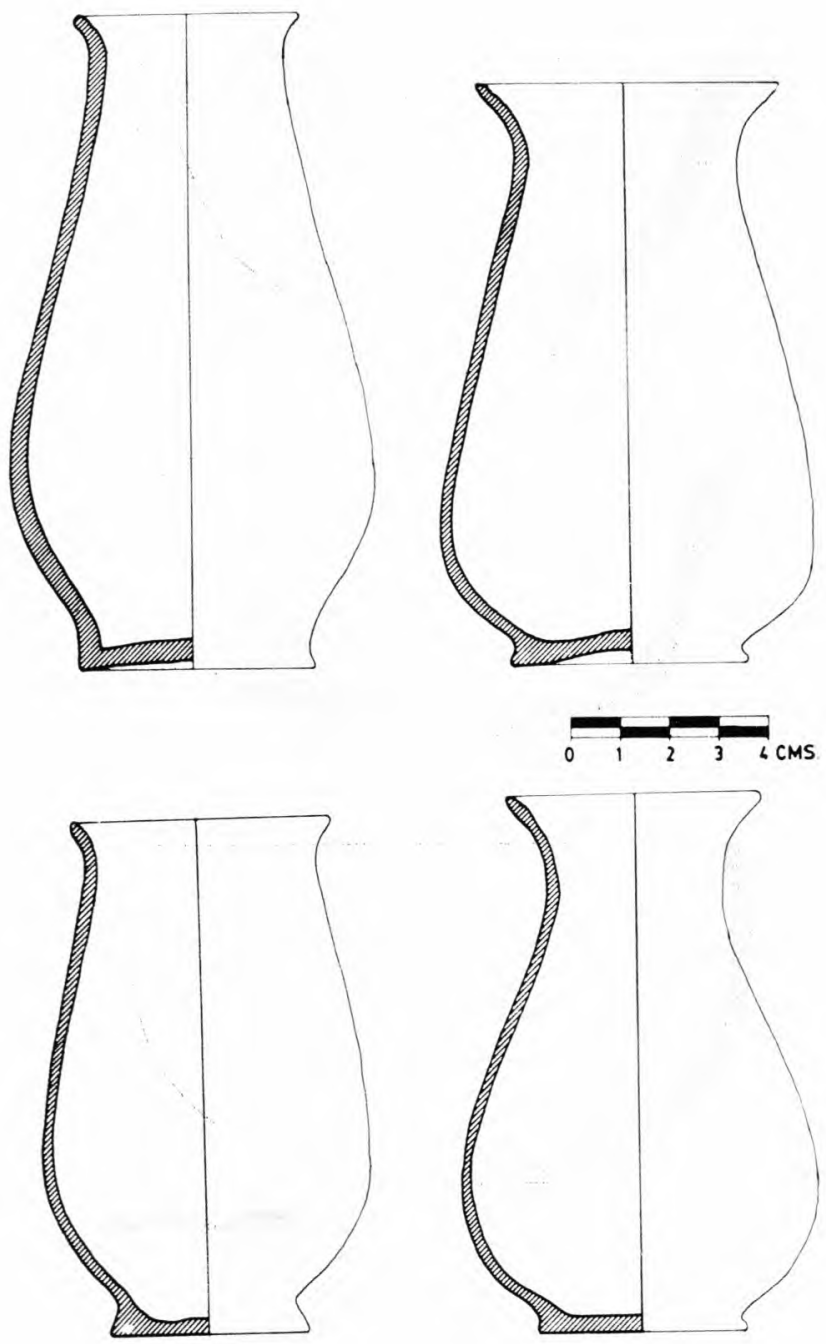

FIG. 5

Cerámica de paredes finas del Castro de Yigo. 

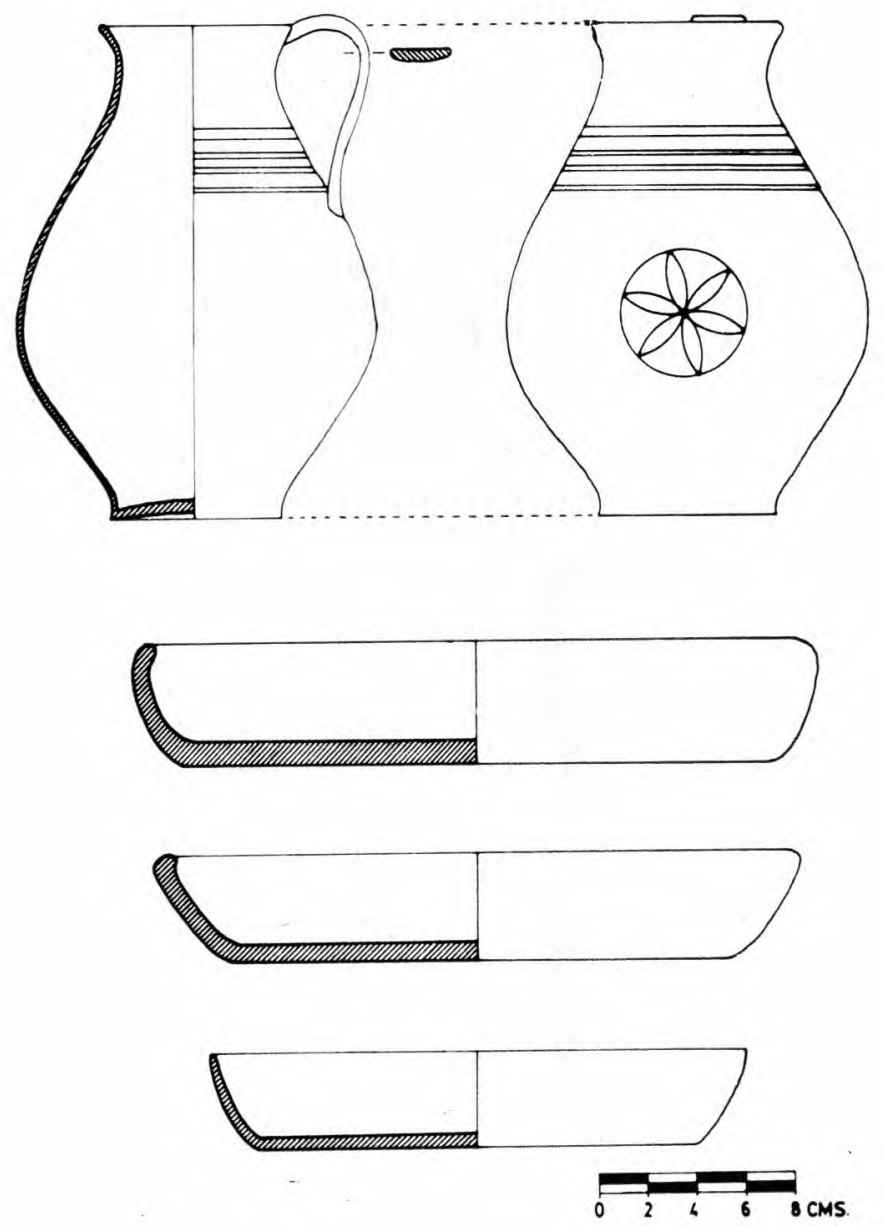

F I . 6

Cerámica común de mesa y cocina del Castro de Vigo. 

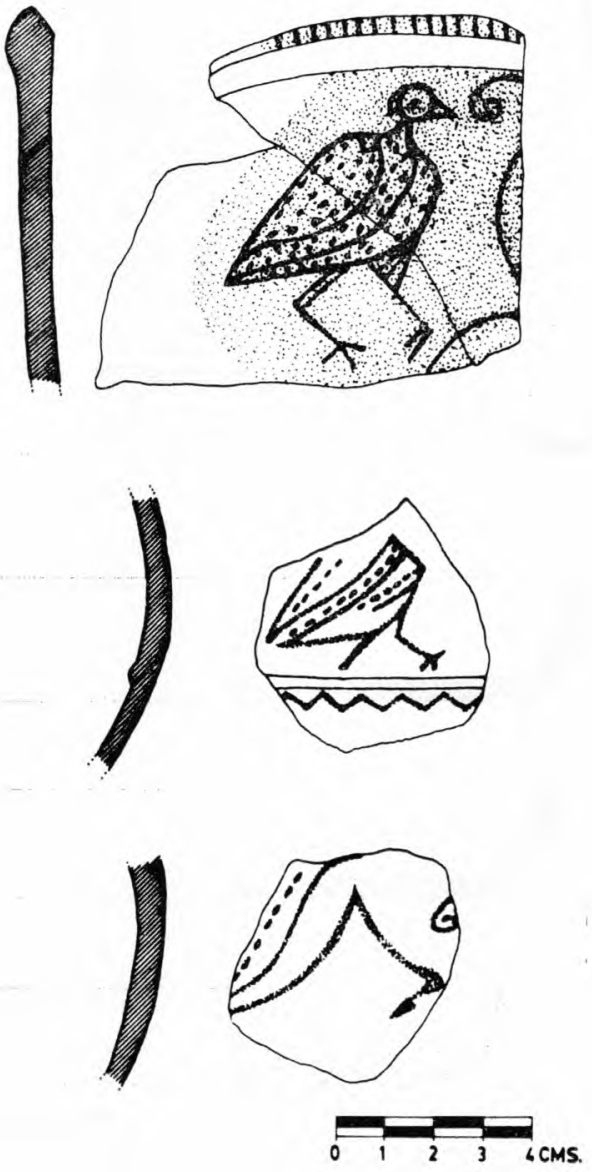

FIG. 7

Cerámica pintada de la villa de Toralia. 

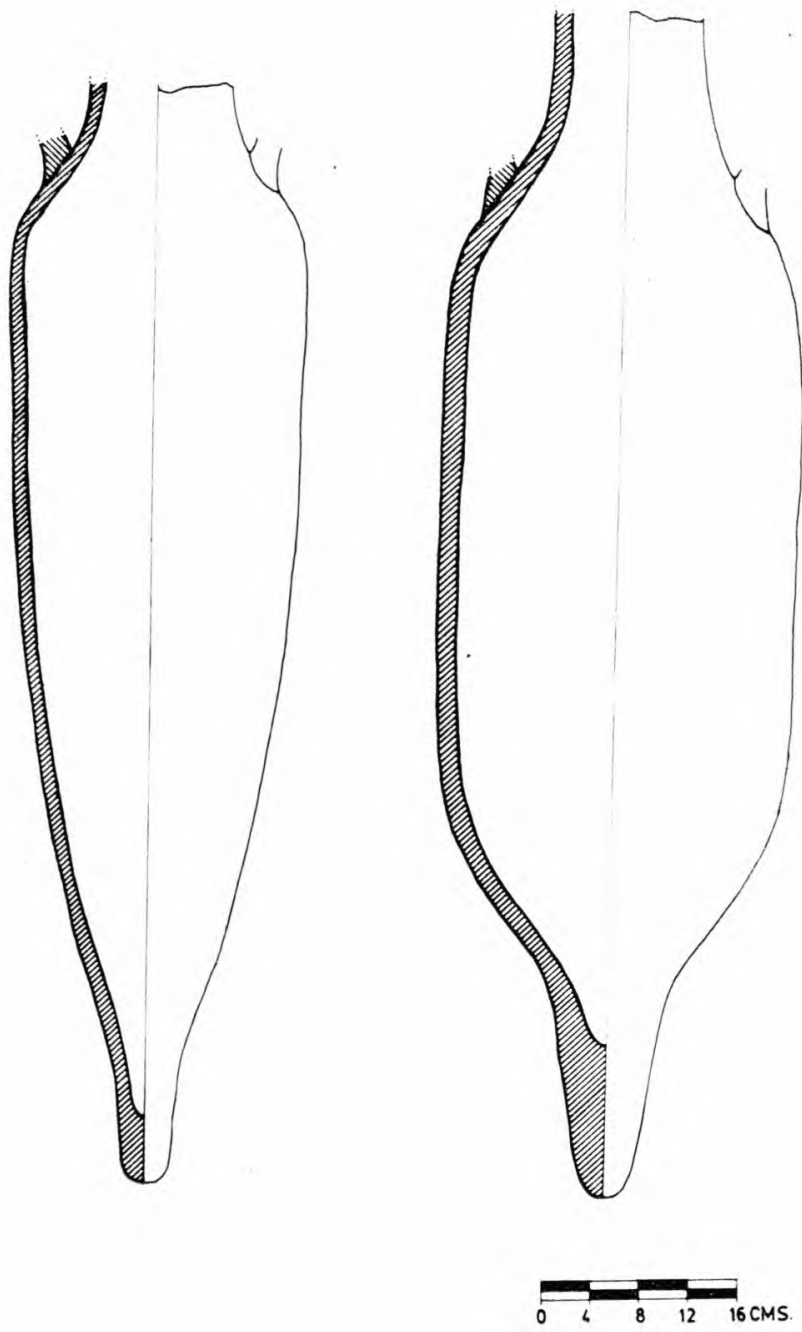

FIG. 8

Hallazgos submarinos de época romana: ánforas de la dársena número 2 del puerto de Yigo y de la isla de Toralia. 